Volume 15 - Número 1 - jan/jul de 2020

\title{
UMA PESQUISA NARRATIVA VIVIDA EM MONITORIAS DE LÍNGUA PORTUGUESA COM DISCENTES INDÍGENAS EM UMA UNIVERSIDADE PÚBLICA NO BRASIL
}

\section{A NARRATIVE INQUIRY LIVED IN PORTUGUESE ENRICHMENT CLASSES WITH INDIGENOUS STUDENTS AT A PUBLIC UNIVERSITY IN BRAZIL}

\author{
Viviane Cabral Bengezen ${ }^{1}$ \\ Thaís Dias Venâncio Ferreira ${ }^{2}$
}

\begin{abstract}
RESUMO: Nesta pesquisa narrativa autobiográfica, uma aluna do curso de Letras e sua orientadora de TCC narram sua jornada de repensar as monitorias de português para estudantes indígenas em uma universidade federal da região Centro-Oeste do Brasil, buscando compreender quem são e quem estão se tornando em relação aos discentes e à pesquisa e quais as concepções de língua(gem), ensino e aprendizagem tiveram como base para suas ações. A perspectiva teórico-metodológica é a pesquisa narrativa segundo Clandinin e Connelly (2015), que têm como foco de investigação as experiências individuais vividas e narradas por meio de histórias, partindo do conceito de experiência conforme Dewey (1938) - com os critérios da continuidade e da interação. Como fundamentação teórica, as autoras baseiam-se no ensino de gêneros orais e escritos no âmbito acadêmico (MAGALHÃES; CRISTOVÃO, 2018; DOLZ, 2014; DIONISIO, 2011; ABREU-TARDELLI e LOUSADA, 2007) e nas concepções e visões de mundo dos pensadores indígenas (WERÁ, 2018, 2019; POTIGUARA, 2019; KRENAK, 2019). Os resultados da pesquisa apontam para as concepções de língua, ensino e aprendizagem, que no início das monitorias embasavam uma didática marcada por racismo linguístico e educação bancária, mas que mudaram ao longo da pesquisa, em relação contínua às histórias de quem as pesquisadoras são e quem estão se tornando, em busca de um ensino antirracista de língua portuguesa na universidade e, consequentemente, por uma formação antirracista de professores de línguas.
\end{abstract}

PALAVRAS-CHAVE: Ensino de português para indígenas. Português como língua adicional. Ensino antirracista de línguas.

ABSTRACT: In this autobiographical narrative inquiry, a student of Languages and her undergraduate thesis supervisor narrate her journey of rethinking the Portuguese enrichment classes for indigenous students at a federal university in the Midwest region of Brazil, seeking to understand who they are and who they are becoming in relation to the students and the research and what the conceptions of language, teaching and learning they had as a basis for their actions. The theoretical-methodological perspective is narrative inquiry according to Clandinin and Connelly (2015), which focuses on individual experiences lived and told through stories, based on the concept of experience according to Dewey (1938) - with the criteria of experience - continuity and interaction. As a theoretical framework, the authors discuss the teaching of oral and written genres in the academic field (MAGALHÃES, CRISTÓVÃO, 2018; DOLZ, 2014; DIONISIO, 2011; ABREU-TARDELLI, LOUSADA, 2007) and the conceptions and world views of indigenous scholars and writers (WERÁ, 2018, 2019; POTIGUARA, 2019; KRENAK, 2019). The results of the research point to the conceptions of language, teaching and learning, which were the basis of a racist practice and banking education, at the beginning. However, those practices changed along the narrative inquiry, in relation to the stories the inquirers lived by, while searching for an anti-racist Portuguese language in universities and hence an anti-racist language teacher education.

\footnotetext{
${ }^{1}$ Doutora em Estudos Linguísticos pela Universidade Federal de Uberlândia. Professora do Programa de PósGraduação em Estudos da Linguagem da Universidade Federal de Goiás - Regional Catalão e Professora da Unidade Acadêmica de Letras e Linguística da Universidade Federal de Catalão. E-mail: vbengezen@gmail.com 2 Licenciada em Letras - Português pela Universidade Federal de Goiás - Regional Catalão. E-mail: thaaisferreeira2014@gmail.com
} 
Volume 15 - Número 1 - jan/jul de 2020

KEYWORDS: Portuguese language teaching for indigenous students. Portuguese as an additional language. Anti-racist language teaching.

\section{Narrativas introdutórias}

Durante o primeiro semestre de 2017, Thaís, estudante do terceiro
período do curso de Letras-Português de uma universidade federal brasileira,
mulher jovem não indígena cuja primeira língua é a portuguesa, candidatou-se a um
edital de monitoria de língua portuguesa. Durante a entrevista, ficou sabendo que o
trabalho seria com um aluno indígena do curso de Enfermagem que falava outra
língua, que seria supervisionada pela coordenação do curso do aluno e que
precisaria elaborar planos de trabalho e ensinar língua portuguesa. Naquele
momento, não tinha clareza de como seria o caminho que ela iria trilhar (era a
primeira vez que teria esse tipo de monitoria na universidade) e com quem/se
contaria como supervisão para a elaboração de planos de ensino, materiais,
metodologias, avaliações etc. Na sua cabeça (um pouco medrosa), havia diversas
suposições, pois era tudo muito novo e ela não sabia por onde começar. Ela ficava
se perguntando "Como seria ensinar língua portuguesa para um indígena?"; "Eu
deveria colocar a gramática como ponto de partida?"; "Qual deveria ser o objetivo
do professor de Português?"; "Sou uma discente do terceiro período, será que estou
preparada?"

Texto de campo - Reconstrução de memória da Thaís, outubro de 2019

Na lembrança relatada por Thaís, sobre o início do trabalho de monitoria, percebemos inquietações, angústias e incertezas de uma aluna de Letras em relação ao ensino de português. Thaís se sentia insegura porque não teve tempo de se preparar, nem teve um profissional do departamento de Letras para nortear seu caminho com foco no processo de ensino e aprendizagem da língua portuguesa: nos gêneros que deveriam ser lidos e produzidos por discentes indígenas matriculados em cursos de graduação na universidade, no lugar da gramática nas monitorias, nas dificuldades encontradas por alunos na graduação, na hora de produzir textos pertencentes a gêneros da esfera acadêmica e nos desafios da sala de aula.

Thaís trabalhou como monitora de português para indígenas até o final do seu curso de Letras (dezembro de 2019), com um grupo de quase dez discentes matriculados nos cursos de Psicologia, Ciências Biológicas, Enfermagem e Medicina. No último ano do curso de Letras, Thaís procurou Viviane, uma docente do curso de Letras, para orientá-la em seu Trabalho de Conclusão de Curso (TCC). A aluna decidiu desenvolver uma pesquisa narrativa segundo Clandinin e Connelly (2015) - autores canadenses que têm como foco de investigação as experiências vividas e, principalmente, quem as pessoas são e quem estão se tornando nos contextos de pesquisa. Thaís e Viviane entendem que muitos problemas poderiam ter sido solucionados com mais eficiência se Thaís tivesse tido acesso às experiências vividas e narradas por ela.

Portanto, esta pesquisa se justifica porque pode contribuir para auxiliar os estudantes indígenas que estejam aprendendo língua portuguesa na graduação, para professores de português e para monitores (alunos do curso de Letras). Além disso, pode contribuir para nossa própria formação acadêmica e para outros pesquisadores da área de Linguística Aplicada que buscam refletir, problematizar e pensar ações futuras para essas práticas. Por meio da investigação das histórias, esperamos que seja possível pensar estratégias de ensino que sejam eficazes e significativas para a preparação de planos de trabalhos e atividades didáticas a serem 
Volume 15 - Número 1 - jan/jul de 2020

trabalhadas na universidade, no contexto de português como língua adicional para estudantes indígenas.

Nosso objetivo geral, ao desenvolvermos esta pesquisa, é apresentar narrativamente as histórias das experiências vividas durante a monitoria de Língua Portuguesa para discentes indígenas em uma universidade federal da região Centro-Oeste do Brasil, buscando compreender quem somos e quem estamos nos tornando em relação aos discentes e à pesquisa e quais as concepções de língua(gem), ensino e aprendizagem tivemos como base para nossas ações. Nossos objetivos específicos são investigar as experiências de elaboração dos planos de trabalho e de supervisão da monitoria, durante os dois anos e seis meses de monitoria de língua portuguesa. Para atingir nossos objetivos, estruturamos a seguinte questão de pesquisa: Que concepções de língua(gem), ensino e aprendizagem tivemos como base para nossas ações quando vivemos experiências de monitoria de Língua Portuguesa para discentes indígenas em uma universidade federal da região Centro-Oeste do Brasil?

Este artigo está organizado da seguinte forma: na introdução, a partir de uma reconstrução de memória, estruturamos nossos objetivos e questão de pesquisa, apresentamos a justificativa para o desenvolvimento da investigação e selecionamos o caminho teóricometodológico trilhado tendo em conta a problemática de investigação. Na seção do caminho teórico-metodológico, apresentamos a pesquisa narrativa e os conceitos que a fundamentam, bem como a composição dos textos de campo, a transição para os textos de pesquisa e a composição de sentidos. Em seguida, contamos e recontamos as experiências vividas, atentas às tensões observadas, à nossa questão de pesquisa, à audiência e à área em que esta pesquisa está inserida - a Linguística Aplicada, problematizando questões relacionadas com: i) os povos indígenas, a aprendizagem da língua portuguesa e o posicionamento dos indígenas na universidade, conforme Werá (2018, 2019), Potiguara (2019), e Krenak (2019); e ii) o ensino de gêneros orais e escritos, conforme Magalhães e Cristóvão (2018), Dolz e Schneuwly (2014), Dionísio (2011) e Machado, Abreu-Tardelli e Lousada (2007).

\section{$2 \mathrm{O}$ caminho teórico-metodológico: a pesquisa narrativa}

Quando Thaís decidiu escrever sobre as experiências vividas nas monitorias, ela não sabia qual caminho percorrer para que suas histórias pudessem ser contadas. Sua vontade de falar sobre toda sua vivência era grande, mas tinha receio de que não fosse possível contar da maneira que ela gostaria - devido aos tentáculos da academia (MELLO, 2018), que tentavam imobilizá-la - abordando uma temática de ensino com alunos indígenas, em uma universidade que ela sentia que não estava preparada para acolhê-los. De acordo com Clandinin e Connelly (2015, p. 80):

Quase todos nós - é quase inimaginável que não fizéssemos isso - vamos para a pesquisa narrativa com diversas versões de histórias de pesquisa formalistas e reducionistas. Isso é tão verdade que estamos sempre nos debatendo com tensões pessoais ao continuarmos nossa pesquisa narrativa.

A partir dos critérios de experiência (continuidade e interação), Clandinin e Connelly (2015, p. 85) apresentam o conceito do espaço metafórico tridimensional da pesquisa narrativa:

[...] em nossa concepção sobre a pesquisa narrativa, nossos termos são pessoal e social (interação); passado, presente e futuro (continuidade); combinados à noção de lugar (situação). Este conjunto de termos cria um espaço tridimensional para a investigação narrativa, com a temporalidade ao longo da primeira dimensão, o pessoal e o social ao longo da segunda dimensão e o lugar ao longo da terceira. Utilizando esse conjunto de termos, qualquer 
Volume 15 - Número 1 - jan/jul de 2020

investigação particular é definida por este espaço tridimensional: os estudos têm dimensões e abordam assuntos temporais; focam no pessoal e no social em um balanço adequado para a investigação; e ocorrem em lugares específicos ou sequências de lugares.

Sendo assim, analisar uma experiência vivida é explorar concomitantemente em quatro direções (retrospectiva, prospectiva, introspectiva e extrospectiva), apresentando indagações relacionadas a cada um desses caminhos. Quando nos posicionamos em algum desses espaços bidimensionais em qualquer que seja a investigação, criamos perguntas, compomos textos de campo, escrevemos textos de pesquisa que atendam às questões pessoais e, também, às sociais, olhando para dentro de nós mesmos de uma maneira interna e externa, desenvolvendo questões temporais considerando não apenas o acontecimento, mas seu passado e futuro.

Quando vamos a campo, já temos uma história que passa a se correlacionar com a história que criaremos ao longo da pesquisa. Isso tem que ser levado em consideração durante a composição dos textos de campo (coleta de dados), e durante a transição dos textos de campo aos textos de pesquisa intermediários, até chegarmos aos textos de pesquisa, por meio da composição dos sentidos (análise dos dados). Thaís percebeu como as histórias que a constituem $^{3}$ influenciam suas práticas de ensino de língua portuguesa. A importância de investigar as experiências, segundo Clandinin e Connelly (2015, p. 108): "é o crescimento e a transformação na história de vida [...]", contar histórias vividas pode ser algo difícil, mas recontar as histórias, permitindo desenvolvimento e mudança, é ainda mais, pois nos deparamos, muitas vezes, com nossa vulnerabilidade, fragilidades, preconceitos, julgamentos, insegurança e limitações.

Entretanto, construir narrativas a partir da investigação das experiências vividas tem um potencial transformador das práticas docentes, à medida que vivemos, contamos, recontamos e, talvez, revivemos nossas experiências. Quando Thaís começou a pensar narrativamente, durante sua pesquisa em 2019, contou as histórias das experiências que vivenciou como monitora de língua portuguesa para discentes indígenas e, ao se engajar na pesquisa narrativa e nas comunidades responsivas ${ }^{4}$, pôde entender esses momentos como espaços de visibilidade que a ajudaram a estar no mundo e viver de formas diferentes - apesar de permeadas pela vulnerabilidade e insegurança, marcadas, sobretudo, pela coragem e pela vontade de construir outras narrativas como professora, visando à participação democrática e inclusão. Atentandose a isto, levou em consideração que essa atividade de pensar narrativamente teve um forte impacto nas suas práticas, pois "os textos de campo permitem crescimento e mudança ao invés de fixar relações entre ideias e fatos" (CLANDININ; CONNELLY, 2015, p. 137).

Quando começamos a co-compor os textos de campo, Viviane, a orientadora, pedia para que Thaís escrevesse histórias: história do que ela sabia sobre indígenas desde a infância, história dos planos de trabalho que ela já tinha elaborado para as monitorias, histórias das monitorias produtivas que ela estava vivendo com os alunos indígenas etc. Para que este trabalho pudesse ser construído, compusemos diversos textos de campo: as histórias da elaboração dos planos de trabalho, notas de campo durante as monitorias e os encontros de orientação e conversas sobre ensinar e aprender língua portuguesa. Com os textos de campos compostos, começamos a atividade de passá-los para este texto de pesquisa, analisando-os e

\footnotetext{
${ }^{3}$ Histórias que nos constituem ou que nos identificam ("stories to live by") é um termo narrativo para identidade (CONNELLY; CLANDININ, 1999).

4 Para Clandinin (2018), comunidades responsivas são como um espaço de visibilidade. Sabemos que nossas experiências em comunidades responsivas nos permitem estar e viver no mundo de formas diferentes, formas marcadas pela vulnerabilidade e pela coragem. Também nos baseamos no trabalho de estudiosos pragmáticos, como Dewey (1938) e Addams (1990), que entendem o diálogo nas comunidades democráticas e que convidam para uma democracia mais participativa e para um entendimento da inclusão que reconheça e possa ser levada em consideração nas experiências do cotidiano.
} 
adaptando-os, considerando que "o processo de mover-se dos textos de campo para os de pesquisa é muito mais complexo" (CLANDININ; CONNELLY, 2015, p. 177).

A análise dos dados, na pesquisa narrativa, é entendida como a composição de sentidos da experiência. Na transição, ao transformar textos de campo em textos de pesquisa, consideramos e retomamos a justificativa de pesquisa, o fenômeno, o método, a forma de interpretação-análise, o espaço da literatura teórica, o posicionamento, e o tipo de texto desejado e composto, com um cuidado constante na relação ética entre as pessoas, os objetivos de pesquisa e a relevância social do estudo. Durante a análise narrativa, procuramos responder a questões sobre quem, por quê, o quê e como, principalmente com atenção ao contexto de pesquisa e à forma que escolhemos para expressar e divulgar os resultados - formas que valorizem a experiência vivida - as vidas das pessoas.

\section{Contando a história da experiência vivida}

De 2017 a 2019, Thaís vivenciou, nas monitorias de língua portuguesa para discentes indígenas, momentos que viveram de forma mais descontraída e menos formais, mas, também, muitos momentos de tensões. Para este trabalho, nosso foco será a experiência que ela teve ao elaborar planos de trabalho para as monitorias, pois nesses momentos ela enfrentou muitas dúvidas, dificuldades, desafios e inseguranças. Para investigar essas experiências, utilizamos a história de elaboração do primeiro plano de trabalho de Thaís, feito no primeiro semestre de 2017. Depois de narrar as experiências, co-compusemos sentidos conforme os pressupostos de Ely et al. (2005) e construímos cinco narrativas, pensando nos objetivos e questão de pesquisa, imaginando quem são os possíveis leitores, com foco nas justificativas pessoal, prática, social e acadêmica desta pesquisa e atentas às tensões vivenciadas, às aprendizagens, às transformações e aos pontos mais fortes das narrativas quando sentimos que estávamos mudando quem éramos, quem somos, quem estamos nos tornando, como ensinamos língua portuguesa, quais são nossas concepções de língua e qual é o papel dos professores e dos alunos no processo de ensino e aprendizagem de línguas.

\subsection{A história da elaboração do primeiro plano de trabalho}

Em 2017, havia apenas um aluno indígena matriculado na universidade pesquisada. O primeiro plano de trabalho que Thaís elaborou para as monitorias de Língua Portuguesa foi feito no primeiro semestre de 2017, juntamente com a coordenadora do curso de Enfermagem, que era o curso no qual o discente estava matriculado. $\mathrm{O}$ método adotado para ser o ponto de partida da elaboração do plano de trabalho foi observar os aspectos da comunicação do aluno. Thaís se atentou muito às questões gramaticais e, quando estavam juntos nas primeiras monitorias (para se conhecerem e elencar o que seria proposto no plano) ela observou como ele pronunciava as palavras em português, a maneira como escrevia e como lia.

A coordenadora já convivia com o aluno desde 2016 (ano que ele ingressou no curso) e, por isso, Thaís concluiu que ela já estava mais familiarizada com ele. Ela se recorda de momentos que a coordenadora falava sobre os costumes dos indígenas, dos eventos acadêmicos que já havia participado e que abordavam essa temática, e Thaís foi se dando conta de que tudo que sabia sobre indígenas era com base no senso comum e em uma visão estereotipada reproduzida ao longo dos anos. Em relação às monitorias de língua portuguesa, os professores das disciplinas cursadas pelo discente indígena julgaram algumas dificuldades do aluno, tais como: socialização com os colegas de classe, dificuldades de se expressar nas apresentações de trabalho, dificuldade de escrita de trabalhos e significado das palavras. Com base nesses julgamentos, Thaís elaborou um primeiro plano de trabalho: 


\begin{abstract}
A) OBJETIVOS - Objetivo Geral: Mediar o processo de aquisição da Língua Portuguesa. Objetivos Específicos: i) Ensinar concordância verbal em textos escritos e na oralização; ii) Instruir o uso adequado de acentuação e pontuação; iii) Ensinar a pronúncia de forma correta das palavras no Português; iv) Instruir o uso de palavras no singular e no plural na leitura e na escrita; v) Auxiliar a interpretação de texto; vi) Aprimorar a escrita do aluno monitorado.

B) ESTRATÉGIAS - i) Uso de dicionários: Língua Portuguesa e Termos técnicos (impresso e online); ii) Reescrita de textos; iii) Utilização de imagens; iv) Acompanhamento nas avaliações.

C) ATIVIDADES A SEREM DESENVOLVIDAS - i) Leitura de textos, diferença entre singular e plural, uso de "m" antes de "p" e "b", acentuação, pronúncia das palavras, pontuação, tradução de significados e ensino de como pesquisar no dicionário. Vogais, consoantes (pronúncia e uso em palavras) e ensino de redação e textos acadêmicos; ii) Utilização dos textos das disciplinas do curso (Enfermagem) para executar as atividades diárias (leitura, escrita, pronúncia); iii) Uso do dicionário para tradução de significados; iv) Reescrita de textos para aprimorar a escrita; v) Acompanhamento nas atividades avaliativas e em monitorias do aluno para auxiliá-lo com tradução de significados, estruturação do texto e entendimento do que se pede (interpretação); vi) Utilização de imagens para auxiliar a compreensão de singular e plural.
\end{abstract}

Texto de campo - plano de trabalho 1, elaborado por Thaís, em 2017/1

O plano de Thaís tinha três partes: objetivos, estratégias e atividades a serem desenvolvidas. Nos objetivos, por exemplo, ela propunha mediar o processo de aquisição da Língua Portuguesa. Na segunda parte do plano - "estratégias propostas", Thaís apresentava o uso de dicionários, reescrita de textos, utilização de imagens e o acompanhamento nas avaliações. Na última parte, intitulada "Atividades a serem desenvolvidas", ela fez uma primeira tentativa de sistematizar quais atividades seriam desenvolvidas e como, até atingir os objetivos propostos.

\title{
4 Recontando a história e compondo sentidos da experiência
}

Ao ler essa história dois anos depois de ter vivido a experiência, Thaís começou a entender que o plano tinha problemas, e começou, também, a transformar sua história de monitoria de português para discentes indígenas. Entendemos que o maior desafio enfrentado na época e que está diretamente relacionado à formação de professores, foi o fato de Thaís ter se responsabilizado pelas monitorias praticamente sozinha. É quase impossível que um aluno do curso de Letras seja monitor de língua portuguesa sem a orientação de um docente da área da Letras e sem um grupo de apoio para compartilhar as experiências vividas nas monitorias, refletir sobre as práticas, as interações, as avaliações, avaliar o que funciona e o que não funciona, para aprimorar as práticas.

Ao analisarmos o plano como um todo, não entendemos como Thaís estava conectando as atividades e as estratégias de ensino, para atingir os objetivos propostos. O resultado é um plano de trabalho que não faz sentido, pois não apresenta sistematicamente qual será a sequência de atividades propostas ao discente nas monitorias.

Embora o plano não estivesse bem estruturado, consideramos válido o trabalho de Thaís, que era uma discente recém chegada ao curso de Letras, reconhecendo que foi uma primeira 
Volume 15 - Número 1 - jan/jul de 2020

tentativa de planejar as monitorias de língua portuguesa como língua adicional ${ }^{5}$ para discentes indígenas. Se não tivesse iniciado esse trabalho e se não tivesse investigado essas experiências de monitoria, talvez não fosse possível transformar sua prática e desconstruir as concepções de língua, linguagem e cultura que permeavam suas ações e reflexões.

\subsection{Racismo linguístico, preconceito linguístico e foco na gramática}

Outro aspecto que chama a atenção no plano que Thaís elaborou em 2017 foi que o plano expressa preconceito linguístico ${ }^{6}$, desconsiderando o contexto social do aluno, a maneira como sua língua materna influenciava na pronúncia de palavras em português e em que contexto ele estava utilizando essa língua, que era no curso de graduação em Enfermagem. Ao conversar com sua orientadora de TCC e refletir sobre o plano, Thaís observa:

Como seria ensinar a pronúncia correta de palavras? Qual seria a pronúncia correta, aliás? Haveria uma maneira única de falar, com a mesma entonação, de forma padronizada, desconsiderando os sotaques, as variedades linguísticas e todas as diversidades que há em qualquer língua do mundo? Além disso, a gramática era o ponto de partida e chegada, era meu foco em todo o plano. Esse ensino parece sem sentido.

Texto de campo - diário reflexivo de Thaís, setembro de 2019.

As reflexões de Thaís, ao analisar o plano que tinha elaborado em 2017, são muito importantes para iniciarmos uma problematização relacionada ao ensino de língua portuguesa no Brasil tanto na universidade, quanto em contextos escolares. Muitos linguistas têm apontado para o perigo da imposição da norma gramatical no ensino do português. Bagno (1999, p. 15), por exemplo, alerta que "a escola tenta impor sua norma linguística como se fosse de fato, a língua comum a todos os [...] brasileiros, independente de sua idade, de sua origem geográfica, de sua situação socioeconômica, de seu grau de escolarização etc." Entretanto, assim como outras monitoras e professoras de línguas, Thaís não deixou de colocar a gramática como a estrela do seu plano de ensino. Não queremos dizer que a gramática não deva ser ensinada, uma vez que ela está presente em todos os gêneros orais e escritos que lemos e produzimos. A questão é o lugar da gramática nas aulas, as formas como ensiná-la e, principalmente, a atenção ao preconceito linguístico que permeia as relações de poder em uma sociedade que julga, exclui e discrimina quem subverte em vez de se submeter. Na história da elaboração do último plano de trabalho de Thaís, refletimos como a gramática seria trabalhada, com base em Bengezen (2010, p. 129), que especificamente na seção "Trabalhando com o conhecimento sistêmico da língua" apresenta um quadro sistematizando os aspectos gramaticais trabalhados nas aulas do primeiro semestre de uma universidade pública brasileira. Sob essa mesma perspectiva, ZolinVesz e Jesus (2019, p. 113), ao criticarem o formato $3+1^{7}$ dos currículos dos cursos de Letras, argumentam que

\footnotetext{
${ }^{5}$ No início das monitorias, Thaís utilizava o termo língua de acolhimento, pois era como ela entendia suas práticas na monitoria. Ao longo da pesquisa, percebeu que, para os estudantes indígenas, portuguesa era a língua do colonizador que causara o genocídio dos povos indígenas no Brasil e, por isso, passou a chamar de língua adicional - uma língua que era necessária aos estudantes indígenas para que atingissem seus objetivos acadêmicos na universidade.

${ }^{6}$ Entendemos preconceito linguístico conforme Bagno $(1999,2008)$, como uma mitologia que deve ser combatida, por ser alimentada pelo binarismo certo e errado e por resultar em juízo de valor de reprovação, de repulsa e de desrespeito às variedades linguísticas de menor prestígio social.

${ }^{7} 3$ anos de estudo da língua e 1 ano de práticas de estágio.
} 
Volume 15 - Número 1 - jan/jul de 2020

engendrados no paradigma monolíngue, continuamos a não problematizar suas rígidas e hierárquicas normas, em especial sua concepção de língua como um conceito monocêntrico, tampouco os interesses a que serve. E, assim, mantemos, virtuosamente estremes, tanto seu privilégio quanto a racionalidade instrumental nas práticas curriculares do curso de Letras.

Além do preconceito linguístico (BAGNO, 2008), o conceito de racismo linguístico (NASCIMENTO, 2019) foi fundamental para nos ajudar a compreender as experiências de monitoria de língua portuguesa para estudantes indígenas. Seguindo o pensamento desse autor, de que o "conceito de 'língua' no ocidente [...] deriva do fetiche entre a perfeição prometida pelo projeto de modernidade e sua performance baseada no mundo greco-romano", entendemos que a concepção de língua que influenciava as monitorias configurava-se como uma marca da dominação, bem como ocupando uma posição do racismo estrutural. Nascimento (2019, s/p.) explica que

Se formos pensar de maneira hegemônica, a língua insere no pensamento não só o que é a coisa significada, mas produz as situações relacionais que dão significado aos sujeitos e às estruturas de poder. Assim, ela produz sempre dicotomias, não porque nela existem dicotomias naturais, mas como reflexo refratado dos próprios projetos de dominação e poder.

As histórias vividas, contadas e recontadas neste artigo são uma oportunidade de iniciarmos uma reflexão sobre o currículo do curso de Letras, que continua com uma estrutura engessada e "engendrado no paradigma monolíngue", impedindo o surgimento de práticas inclusivas, emancipadoras e inovadoras, com grupos formados por diversas pessoas em busca de negociação de sentidos para práticas futuras. Em paisagens educacionais cada vez mais marcadas pela presença de discentes indígenas, como a que foi contexto desta pesquisa, é urgente o fortalecimento tanto de uma perspectiva antirracista de ensino de língua portuguesa, quanto de uma formação antirracista de professores de línguas.

\subsection{O perigo da história única sobre o discente indígena}

Outra tensão que percebemos nessa história é em relação ao que Thaís sabia sobre os indígenas. Retomamos Adichie (2019), para problematizar o perigo da história única que ela tinha sobre os discentes indígenas. Todas as histórias sobre indígenas que ela viveu durante a maior parte de sua vida foram apresentadas com visões estereotipadas. Na escola, ela se lembrava das aulas de História e dos livros didáticos, que expunham o "descobrimento" do Brasil. Não apresentavam a história da colonização, das invasões estrangeiras, das doenças como varíola, sarampo, gripe e tuberculose, entre outras, que exterminaram milhões de indígenas em poucos séculos. Na escola, ela tampouco aprendeu sobre os danos causados às mulheres indígenas, como "violência, [...] racismo e [...] todas as formas de intolerância referentes inclusive à espiritualidade e às culturas indígenas" (POTIGUARA, 2019, p. 23).

Com a oportunidade de estar no Núcleo de Acessibilidade, participando de atividades junto aos alunos indígenas, Thaís pôde viver uma história diferente da história única que possuía até então sobre povos indígenas. Os indígenas brasileiros têm, nas últimas décadas e ainda que lentamente, ocupado cada vez mais os espaços públicos aos quais pertencem e que têm o direito de frequentar (WERÁ, 2018b). Na universidade pesquisada, em 2016, havia apenas um discente indígena matriculado, e em 2019 já contava com oito alunos indígenas. Para os indígenas, estarem inseridos em um local que utiliza como língua padrão o Português é uma das formas de fazer resistência e oposição à ordem estabelecida na sociedade. 
Segundo Daniel Munduruku (WERÁ, 2018b), professor indígena Munduruku do Pará, aprender português e estar nesses locais fora das aldeias não significa deixar de ser indígena, mas levar condição de sobrevivência a seus povos e resistir. O autor afirma, ainda, que os indígenas se mantêm atualizados, constroem conhecimentos, utilizam a fala e a escrita, as tecnologias e os recursos acessíveis no século XXI, já que estão imersos em uma sociedade que muda a cada dia, como povos que lutam para manter sua própria cultura viva e participar ativamente nas comunidades onde vivem.

Em relação às diversidades tecnológicas a que temos acesso na atualidade, o autor nos traz uma visão sobre a escrita ressaltando que, para os indígenas, "[...] o domínio da escrita como instrumento é uma coisa recente. Nós não escrevíamos como o ocidente escreve, mas nós aprendemos. Então, para nós, é uma tecnologia" (WERÁ, 2018b, p. 114). É de grande importância trazer a escrita para o processo de construção de identidades, principalmente de identidades que são estereotipadas e que, consequentemente, sofrem ataques e opressões que geram a agressão e exclusão. A ocupação dos espaços, simplesmente, não garante a conquista de direitos, pois ainda há muito o que caminhar neste país. Mesmo a Constituição brasileira de 1988 garantindo os direitos dos indígenas, os governos brasileiros têm insistido em tornar os locais inacessíveis ou, com muita luta, pouco frequentáveis.

Entendemos que, ao decidir pesquisar as experiências de Thaís e Viviane nas monitorias para discentes indígenas na universidade, em um espaço que está começando a recebê-los e tem muito para aprender, temos responsabilidade em publicar o máximo de informações possível para que as pessoas possam, ao menos, iniciar um processo de questionamento da história única que consideram sobre os indígenas nas Américas.

\subsection{O que faz sentido no ensino de português para indígenas?}

Considerando a monitoria de Língua Portuguesa para estudantes indígenas na universidade, entendemos ser necessário discutir algumas questões em relação a como seria ensinar língua portuguesa para indígenas; qual o lugar da gramática e como poderia ser concebido o papel do professor de Português. Para embasar tal discussão, abordamos o ensino e aprendizagem de gêneros orais e escritos:

[...] É bastante comum na escola e na universidade que se solicite aos alunos a produzirem textos na oralidade e na escrita sem que se ensine como fazer isso, como por exemplo o que ocorre com os seminários escolares, as resenhas, as monografias [...] Isso ocorre muitas vezes porque essa produção de texto é pretexto para aprendizagem da língua, isolando tais produções dos contextos reais da ação da linguagem. Essa prática é resultado do que Street chamou de letramento autônomo [...] em que a aprendizagem de uma escrita "única" e universal, independente dos contextos sociais, formaria sujeitos capazes de escrever todo e qualquer texto, bastando os alunos saberem ler e escrever bem para agirem socialmente por meio de gêneros de diferentes esferas (MAGALHÃES; CRISTÓVÃO, 2018, p. 30).

Quando Thaís recorda o início de sua graduação, ela se lembra do quanto desesperador foi não saber produzir algo que o professor pedia que entregasse em sala de aula. As dúvidas que o aluno indígena trazia para as monitorias eram muito parecidas com as dela e de diversos alunos de graduação da universidade. Em geral e em qualquer fase do desenvolvimento do currículo escolar, os professores solicitam resenhas, resumos, seminários, portfólios e vários outros gêneros acadêmicos, sem buscar saber se os alunos têm confiança para produzir tais textos. 
Aprender a ler e produzir textos é essencial ao desenvolvimento do indivíduo em uma sociedade, pensando nos letramentos como práticas sociais para o exercício da cidadania. Por meio da obtenção, compreensão e construção do conhecimento que circula no mundo em que vivemos, onde muito é compartilhado seja pela oralidade ou por escrito, as pessoas se tornam parte do meio, podendo fazer o exercício coerente de interpretação dos fatos e sendo protagonista de sua própria história - podendo se expressar e reivindicar suas necessidades. Se levarmos em consideração que a língua é multimodal, ou seja, é realizada/usada de diversas maneiras, então entendemos que gêneros textuais também são multimodais, pois "quando falamos ou escrevemos um texto, estamos usando no mínimo dois modos de representação: palavras e gestos, palavras e entonações, palavras e imagens, palavras e tipografias [...]" (DIONISIO, 2011, p. 139).

Nesse sentido, entendemos que os alunos indígenas precisam se apropriar dos gêneros para expressar seus pensamentos e emoções, seus posicionamentos, sua visão de mundo, cultura e identidades. Dionisio (2011, p. 139) diz que "quando usamos linguagem, estamos realizando ações individuais e sociais que são manifestações socioculturais, materializadas em gêneros textuais". Teria sido fundamental que Thaís, como monitora de língua portuguesa, fosse supervisionada por um(a) docente do curso de Letras, pois são necessários conhecimentos da área, tais como o ensino sistemático dos gêneros orais e escritos na universidade, orientado por material didático cientificamente instrumentado, pensando na escrita como processo, na intrínseca relação entre leitura e escrita, e nos movimentos e passos retóricos que compõem cada gênero acadêmico.

Era necessário que Thaís tivesse um embasamento teórico decolonial para articular a pedagogia dos gêneros e a teoria sociocultural de aprendizagem a uma decolonização do ensino de línguas em contextos indígenas, buscando desenvolver os planos de trabalho das monitorias de forma colaborativa com professores e pesquisadores indígenas, considerando e valorizando as vidas nas aldeias, as comunidades, as culturas e os conhecimentos.

Felizmente, no último ano de monitoria, Viviane passou a orientar Thaís, trilhando o caminho da pesquisa narrativa e chamando sua atenção ao fato de que, para ensinar e aprender uma língua, é preciso considerar aspectos sociais, políticos, ideológicos, culturais e metodológicos. Assim, Thaís começou a viver e contar uma história diferente de monitoria de língua portuguesa para discentes indígenas na universidade.

\subsection{O início da transformação com um novo plano de trabalho}

A experiência que Thaís conta agora é do último plano de trabalho que fez não somente para um único aluno indígena (como acontecia até o penúltimo semestre de 2019) mas para cinco alunos indígenas que se matricularam na universidade no ano de 2019. Além de ministrar monitoria em conjunto com todos eles, ela propôs, ainda, um acompanhamento individual de dois alunos da etnia Xavante (cuja língua materna é o A’uwe). Um deles é o aluno que ela estava acompanhando desde 2017 e o outro ingressou somente em 2019. Thaís disponibilizou, então, uma carga horária exclusiva para eles. Ela também disponibilizava horas para que os demais indígenas marcassem monitorias individuais, caso quisessem reforço em algo relacionado à língua portuguesa. O último plano de 2019 ficou da seguinte maneira:

A) OBJETIVOS - Objetivo Geral: Criar espaços de discussões, aprendizagem e reflexões sobre a língua portuguesa, com foco nos gêneros orais e escritos que circulam no curso de graduação onde os estudantes estejam matriculados. Objetivos Específicos: i) Ofertar oficinas de leitura e produção de gêneros acadêmicos para alunos indígenas na graduação; ii) Abordar o uso das normas da ABNT nos gêneros acadêmicos trabalhados. 
B) ESTRATÉGIAS - i) Atividades de leitura com textos que os alunos trarão dos seus cursos, sempre com foco na ética relacional construída entre discentes, monitores e coordenadores; ii) Oportunidades para que os discentes indígenas apresentem à comunidade da UFCAT seus trabalhos, cultura, espiritualidade e visão de mundo; iii) Utilização de vídeos, imagens, áudios, textos verbais, orais e/ou escritos, impressos e/ou digitais; iv) Normas (ABNT) e técnicas de leitura, escrita, interpretação e produção de recursos audiovisuais no âmbito acadêmico; v) Reescrita de textos.

C) ATIVIDADES - i) Leitura e produção de gêneros orais e/ou escritos que circulam nos cursos de graduação onde eles estão matriculados; ii) Reescrita de textos como método de aprimoramento da produção textual, com feedbacks da monitora, considerando a escrita como processo.

Texto de campo - plano de trabalho 2, elaborado por Thaís, em 2019/2

\subsection{Um recomeço com comunidades responsivas e trabalho colaborativo}

Assim que Thaís começou a escrever suas narrativas para o TCC, no início do semestre de 2019, ela também viveu a experiência de participar de um projeto denominado: "Qualidade da Permanência do Estudante Indígena na Universidade: o ensino-aprendizagem com mais sensibilidade, isonomia e equidade". Todos os indígenas matriculados na universidade que quisessem participar desses encontros, poderiam frequentar semanalmente (como ocorria). Nesses encontros semanais, os alunos indígenas, Thaís e os demais participantes falavam de assuntos que enriqueciam as experiências deles tanto na universidade, quanto em suas aldeias (no caso dos alunos indígenas), tais como: estratégias para o exercício profissional nas aldeias sem ferir a cultura, estudo e discussão de textos sobre o território indígena brasileiro, produção de banners sobre diversidade na universidade e, também, sobre os indígenas nesse espaço, dentre outros exercícios.

Participar dessas atividades foi importante para que Thaís prestasse mais atenção a quem eram os alunos das monitorias, quais eram suas histórias vividas, como eles narravam suas experiências e como os processos de ensino e aprendizagem poderiam ser negociados. Ao aprender mais com os estudantes indígenas, Thaís passou a ter mais elementos para compor sentidos de suas experiências. Caminhamos aprendendo com Krenak (2019, p. 59), que diz

Nosso tempo é especialista em produzir ausências: do sentido de viver em sociedade, do próprio sentido da experiência da vida. Isso gera uma intolerância muito grande com relação a quem ainda é capaz de experimentar o prazer de estar vivo, de dançar e de cantar. E está cheio de pequenas constelações de gente espalhada pelo mundo que dança, canta e faz chover.

As monitorias de língua portuguesa para os discentes indígenas avançaram bastante no ano de 2019, pois além da criação dos encontros semanais com os indígenas, Thaís e Viviane perceberam que o plano de trabalho não deveria ser orientado pela coordenação do curso onde os alunos estavam matriculados (já que se tratava de ensino de português), mas por um docente do curso de Letras. Naquela época, Viviane começou a coordenar um projeto de extensão voltado para o ensino de português como língua adicional, cujo foco era criar espaços de discussão, reflexão e práticas de ensino do idioma, envolvendo discentes indígenas matriculados na universidade e aberto a imigrantes, estrangeiros e refugiados. Como Thaís era monitora desse projeto, passou a contar com mais um apoio para (des)(re)construir suas histórias de ensinar língua portuguesa. Observando o último plano de trabalho, ela se viu progredindo, como futura professora de português, e viu sua prática começando a fazer sentido. 
Apesar de o último plano de trabalho ter problemas, ele já avançou muito em relação ao primeiro, que Thaís havia elaborado dois anos antes. Ela compreende que ainda precisa entender melhor essa divisão em três partes e por que estão divididas em objetivos, estratégias e atividades. No curso de Letras, teve aulas que lhe deram oportunidades de aprender sobre sequências didáticas baseadas em gêneros, mas não conseguiu fazer uma transposição didática do que estava aprendendo na graduação para suas práticas nas monitorias. Entretanto, ao investigar essa experiência dos planos de trabalho, Thaís começou a compreender mais profundamente suas concepções de língua, do que é ensinar, do que é aprender e qual o papel do aluno e do professor nesse processo.

Começou a perceber que ela, como professora de língua portuguesa, às vezes reproduzia o modelo de educação bancária exposto e criticado por Paulo Freire (2005), sendo transmissora de conhecimentos e impondo regras sem criar espaços de construção colaborativa de conhecimentos. Thaís começou a entender, também, que a produção de textos realizada pelos alunos é um processo em espiral e não um produto onde sua concepção de língua estava muito voltada para a forma. Hoje, ela entende que a língua está relacionada à constituição identitária de cada indivíduo e que afeta o modo como cada um compõe sentidos, lê e interpreta o mundo. Ao viver essa experiência de monitoria e depois contar as histórias dessas experiências, recontar e reviver, Thaís aprendeu, com Potiguara $(2019$, p. 88$)$, que "uma mulher deve andar com a força à sua frente" e passou a ficar mais atenta a questões relacionadas ao que significa educar para a cidadania global e internacionalização, por exemplo, como as colocadas por Andreotti e Souza (2008, p. 3):

Com muita frequência, as abordagens da educação para a cidadania global na Europa estabelecem as prioridades para o desenvolvimento internacional de uma maneira que deixa suposições sem exame e ignora como essa agenda é reinterpretada em outros contextos. Não abordar essas diferentes leituras pode resultar no reforço acrítico das noções de supremacia e universalidade das 'nossas' formas de ver (ocidentais), que podem reproduzir relações desiguais de diálogo e poder e subestimar outros sistemas de conhecimento.

Esses autores desenvolveram um curso para professores ingleses refletirem sobre ver o mundo através de outros olhos. Entendemos que o material produzido por eles pode contribuir para os contextos de monitoria de língua portuguesa para indígenas, pois fornece ferramentas para que os professores reflitam sobre seus próprios sistemas de conhecimento e se engajem com outros sistemas de conhecimento de diversas maneiras e em diferentes espaços. Precisamos aprender a ler o mundo considerando outros olhares, sistemas de sentidos e representações, em relação a conceitos como "desenvolvimento, erradicação da pobreza, igualdade e educação" (ANDREOTTI; SOUZA, 2008, p. 1), entre outros.

Para citar um exemplo de como estarmos atentas ao ser professora de língua portuguesa para indígenas, destacamos um episódio relacionado ao conceito de desenvolvimento, que foi compartilhado nesse curso supracitado. Um indígena brasileiro, perguntado o que era, para ele, ser desenvolvido, responde que desenvolvimento era ruim. Em sua comunidade, era fundamental que todos estivessem engajados e trabalhassem pensando a coletividade. Porém, quando algum membro da comunidade saía da aldeia para viver como os brancos, ele não se envolvia mais. Tornava-se des-envolvido. Esse exemplo nos ajuda a compreender que precisamos perceber que nossas histórias vividas são afetadas por narrativas sociais, culturais e históricas, e que não podemos ingenuamente acreditar que nossas perspectivas são neutras e objetivas. Por isso, ao viajar para o mundo do outro (LUGONES, 1987), precisamos questionar nossas suposições continuamente, para compor outros sentidos das experiências vividas. 
Volume 15 - Número 1 - jan/jul de 2020

\section{Considerações finais}

Iniciamos essa pesquisa narrativa com o objetivo de compreender narrativamente as tensões relacionadas a ensinar língua portuguesa em monitorias para indígenas de graduação em uma universidade federal do Centro-Oeste do Brasil, atentas a quem somos e quem estamos nos tornando e quais as concepções de língua(gem), ensino e aprendizagem embasaram e influenciaram nossas práticas. Nossos objetivos específicos foram investigar as experiências de elaboração dos planos de trabalho e de supervisão da monitoria, durante os dois anos e seis meses de monitoria de língua portuguesa e compreender narrativamente como ocorreu a elaboração do primeiro plano e do último, o que mudou em relação a eles, quais foram os desafios e as perspectivas de histórias de monitoria futuras.

Co-compusemos os textos de campo das experiências vividas durante os anos de 2017, 2018 e 2019 e, ao final da investigação, atingimos nossos objetivos e respondemos à questão de pesquisa "Quais as concepções de língua(gem), ensino e aprendizagem tivemos como base para nossas ações quando vivemos experiências de monitoria de Língua Portuguesa para discentes indígenas em uma universidade federal da região Centro-Oeste do Brasil?", embora tenhamos em mente que a pesquisa narrativa é marcada por um senso de incerteza e tentativas (CLANDININ, 2020).

Respondendo à questão de pesquisa da forma mais sucinta possível, a noção de língua que influenciava as monitorias da Thaís, inicialmente, era estável e mononormativa, sem respeito às variedades. Compreendemos essa concepção ao recontar as histórias das experiências e ao construir as cinco histórias: Preconceito linguístico e foco na gramática; $\mathrm{O}$ perigo da história única sobre o discente indígena; $\mathrm{O}$ que faz sentido no ensino de português para indígenas?; O início da transformação com um novo plano de trabalho e Um recomeço com comunidades responsivas e trabalho colaborativo. Quanto à concepção de ensino e aprendizagem, no início das monitorias Thaís era influenciava por práticas de educação bancária há muito tempo criticadas.

Thaís, fazendo um traçado em sua memória, de como foi esse caminho, entende que houve muitas coisas que poderiam ser diferentes em sua universidade, se desde o início ela estivesse atenta a quem era o aluno indígena, qual sua etnia, sua história de vida, como ele aprendia e como ele gostaria de aprender, o que ele entendia sobre desenvolvimento, educação e igualdade, por exemplo. Temos práticas ainda colonizadoras e isso é algo que afeta, diretamente, os povos nativos do nosso país. Quando Thaís se lembra de seu primeiro plano de trabalho, percebe que não buscava co-compor sentidos junto com o aluno indígena. A prática era de imposição, pois é nítido o desejo de que ele fizesse tudo que ela acreditava ser o correto, mostrando, também, que tinha atitudes equivocadas e mal pensadas para a elaboração do plano de trabalho.

Todos os planos reproduzidos depois do primeiro, exceto o último, foram muito parecidos um com o outro, pois Thaís não tinha criado um espaço para contar e recontar as histórias de sua prática, não refletia continuamente sobre os planos elaborados, nem fazia parte de um grupo que ajudasse colaborativamente a transformar suas histórias. No exercício de pensar narrativamente, na convivência com outros indígenas e com a oportunidade de ouví-los, de saber um pouco de suas histórias, de suas necessidades acadêmicas, participando do grupo de pesquisa narrativa, orientada por Viviane, apresentando resultados parciais de sua pesquisa em eventos acadêmicos, Thaís iniciou uma jornada diferente, começando a compreender que os caminhos estavam "tortos", seu ponto de partida estava equivocado, não era exatamente daquela maneira que ela auxiliaria os alunos indígenas naquele e em outros espaços. Saber quem eram os alunos e quem ela era em relação a eles foi o primeiro ponto para re(des)construir o plano de trabalho. 
Debater sobre processos de ensino e aprendizagem de língua portuguesa no contexto acadêmico para indígenas, juntamente com a leitura e o estudo de autores que abordam o ensino de gêneros na academia, foi essencial. Além disso, estar sob orientação de uma docente do curso de Letras, que compreende a relação entre língua e os modos de compor sentidos do mundo, fez Thaís entender o poder que uma língua pode ter, tanto para excluir, quanto para aproximar as pessoas, as culturas e os diversos conhecimentos. Há muito o que se caminhar e grandes dificuldades irão chegar, ainda, mas há muita vitória aqui também, há coração, há alma, há amor.

Adichie (2019, p. 32) em sua fala, representa bem o que Thaís viveu durante o tempo em que foi monitora de Língua Portuguesa para indígenas, mostrando o poder de mudança em não vivenciar apenas a história única sobre algo ou alguém: "As histórias importam. Muitas histórias importam. As histórias foram usadas para espoliar e caluniar, mas também podem ser usadas para empoderar e humanizar. Elas podem despedaçar a dignidade de um povo, mas também podem reparar essa dignidade despedaçada."

Thaís se sente animada e rejuvenescida para continuar essa luta, tentando métodos, falhando e acertando e trabalhando junto com pessoas que estão o tempo todo lutando para ter e manter seu espaço no mundo. Essa pesquisa nos ensina o quanto ainda temos que caminhar em relação à representatividade de autores indígenas nos cursos de Letras e na universidade, em geral, em busca de aprendermos a ler o mundo através de outros olhos e outras visões de pensar o mundo, formar comunidades responsivas e compartilhar narrativas, considerando as formas como compartilhamos as narrativas de nossas experiências junto com estudantes indígenas e professores de línguas em formação. Não quisemos compor uma história única, ou uma história estreita que correria o risco de se tornar parte de estatísticas relacionadas a estudantes indígenas na universidade, ou a monitorias de línguas com foco na gramática.

Precisamos escrever artigos, teses e dissertações de uma forma relacional e ética, precisamos ler, conhecer e aprender com autoras e autores indígenas e, com urgência, precisamos "adiar o fim do mundo para poder contar mais história" (KRENAK, 2019). Ao partir dos relatos vividos por Thaís, e publicar as narrativas, buscamos compor textos de pesquisa que permitam aos leitores "viajarem para o mundo do outro com ludicidade" (LUGONES, 1997) e poder imaginar-se nos mundos que estamos tornando visíveis.

\section{Referências}

ADICHIE, C. N. O perigo de uma história única. 1. ed. São Paulo: Companhia das Letras, 2019.

ANDREOTTI, V.; SOUZA, L. M. M. Learning to read the world: Through other eyes. Global Education, 2008.

BAGNO, M. Preconceito linguístico. 3. ed. São Paulo: Loyola, 1999.

BAGNO, M. A língua de Eulália. São Paulo: Contexto, 2008.

BENGEZEN, V. C. Histórias de aprendizagem de língua inglesa e de formação de professores. 2010. 173 f. 2010. Tese de Doutorado. Dissertação (Mestrado em Estudos Linguísticos)Instituto de Letras e Linguística, Universidade Federal de Uberlândia, Uberlândia.

CLANDININ, D. J. Journeys in Narrative Inquiry: The Selected Works of D. Jean Clandinin. New York: Routledge, 2020, 334p.

CLANDININ, J.; CONNELly, M. F. Pesquisa Narrativa: Experiência e História em Pesquisa Qualitativa. Tradução: GPNEP - Grupo de Pesquisa Narrativa e Educação de Professores ILEEL/UFU. 2. ed. rev. Uberlândia: EDUFU, 2015. 250 p.

DIONISIO, A. P. Gêneros Textuais e Multimodalidade. In: KARWOSKI, A. M.; GAYDECZKA, B.; BRITO, K. S. (Orgs.) Gêneros Textuais: Reflexões e ensino. 4. ed. São Paulo: Parábola Editorial, 2011. cap. 7, p. 137-152. 
Volume 15 - Número 1 - jan/jul de 2020

ELY, M. et al. On writing qualitative research: Living by words. London: Taylor \& Francis e-Library, 2005.

FREIRE, P. Pedagogia do oprimido. Rio de Janeiro: Paz e Terra, 2005.

KRENAK, A. Ideias para adiar o fim do mundo. Editora Companhia das Letras, 2019.

LUGONES, M. Playfulness, “world”-travelling, and loving perception. Hypatia, 2(2), 3-19. 1987.

MELLO, D. Palestrante no Painel Entrelaces para a rede de pesquisadoras/es em Narrativas, Gênero e Política, Belo Horizonte - MG, UniBH, 2018. (Comunicação oral).

NASCIMENTO, G. Racismo Linguístico. Editora Letramento. Edição do Kindle.

POTIGUARA, E. Metade cara, metade máscara. São Paulo: Global, 2019.

WERÁ, K. (org.). Ailton Krenak. Rio de Janeiro: Beco do Azougue Editorial Ltda., 2018.

WERÁ, K. (org.). Biraci Yawanawá. Rio de Janeiro: Beco do Azougue Editorial Ltda., 2018a.

WERÁ, K. (org.). Daniel Munduruku. Rio de Janeiro: Beco do Azougue Editorial Ltda., 2018b. 7-152 p.

WERÁ, K. (org.). Eliane Potiguara. Rio de Janeiro: Beco do Azougue Editorial Ltda., 2019.

WERÁ, K. (org.). Sônia Guajajara. Rio de Janeiro: Beco do Azougue Editorial Ltda., 2019a. ZOLIN-VESZ, F. e JESUS, D. M. Práticas curriculares do curso de Letras: vigência da racionalidade instrumental e privilégio do paradigma monolíngue. In: MELLO, D. M.; FELICE, M. I. V. (Orgs). Ensino de Línguas no curso de Letras: práticas, experiências e currículo. Uberlândia : EDUFU, 2019. 220p. Série Linguística in Focus; v.13.

Submetido em 29/04/20

Aceito em 18/07/20 